\title{
The Urokinase Plasminogen Activator Receptor-Associated Protein/Endo180 Is Coexpressed with Its Interaction Partners Urokinase Plasminogen Activator Receptor and Matrix Metalloprotease-13 during Osteogenesis
}

\author{
Lars Henning Engelholm, Boye Schnack Nielsen, Sarah Netzel-Arnett, \\ Helene Solberg, Xiao-Dong Chen, Jose Manuel Lopez Garcia, Carlos Lopez-Otin, \\ Marian Francis Young, Henning Birkedal-Hansen, Keld Danø, Leif Røge Lund, \\ Niels Behrendt, and Thomas Henrik Bugge
}

Oral and Pharyngeal Cancer Branch (LHE, THB), Matrix Metalloproteinase Unit (SN-A, HB-H), and Craniofacial and Skeletal Diseases Branch (X-DC, MFY), National Institute of Dental and Craniofacial Research, National Institutes of Health, Bethesda, Maryland; Finsen Laboratory (LHE, BSN, HS, KD, LRL, NB), Copenhagen, Denmark Departamento de Morfologia y Biología Celular (JMLG) and Bioquimica y Biologia Molecular (CL-O), Universidad de Oviedo, Oviedo, Spain

SUMMARY: The urokinase plasminogen activator receptor-associated protein/Endo180 (UPARAP/Endo180) is a newly discovered member of the macrophage mannose receptor family that was reported to interact with ligand-bound urokinase plasminogen activator receptor (UPAR), matrix metalloprotease-13 (MMP-13), and collagen $\mathrm{V}$ on the cell surface. We have determined the sites of expression of this novel receptor during murine postimplantation development. uPARAP/Endo180 was expressed in all tissues undergoing primary ossification, including the developing bones of the viscerocranium and calvarium that ossify intramembranously, and developing long bones undergoing endochondral ossification. uPARAP/Endo180 mRNA was expressed by both immature osteoblasts and by mature osteocalcin-producing osteoblasts-osteocytes, and was coexpressed with MMP-13. Interestingly, osteoblasts also expressed uPAR. Besides bone-forming tissues, uPARAP/Endo180 expression was detected only in a mesenchymal condensation of the midbrain and in the developing lungs. The data suggest a function of this novel protease receptor in bone development, possibly mediated through its interactions with uPAR, MMP-13, or collagen V. (Lab Invest 2001, 81:1403-1414).

$$
T^{\text {he }}
$$

he plasminogen activation system is an intricate system of serine proteases, protease inhibitors, and protease receptors that governs the conversion of the abundant plasma protease zymogen, plasminogen, to the active protease, plasmin. Plasmin acts directly, or indirectly via the activation of latent matrix metalloproteases, to degrade components of the extracellular matrix in the context of tissue homeostasis, tissue remodeling, and tissue repair (Carmeliet et al, 1994; Danø et al, 1985; Lund et al, 2000; Rømer et al, 1996). In addition to its pleiotropic functions in phys-

Received June 8, 2001.

LHE and BSN contributed equally to the reported studies. This work was supported by the Danish Cancer Society, the Plasmid Foundation, Roskilde, Denmark, and the Danish Biotechnology Program.

Address reprint requests to: Dr. Thomas H. Bugge, Proteases and Tissue Remodeling Unit, Oral and Pharyngeal Cancer Branch, National Institute of Dental and Craniofacial Research, National Institutes of Health, 30 Convent Drive, Room 211, Bethesda, MD 20892. E-mail: thomas.bugge@nih.gov iologic tissue remodeling, the plasminogen activation system is also implicated in the pathogenesis of a remarkable array of important human degenerative diseases, most notably tumor dissemination, vessel wall disease, rheumatoid arthritis, and ischemic brain damage (Busso et al, 1997; Carmeliet et al, 1997; Danø et al, 1985; Ossowski and Reich, 1983; Tsirka et al, 1995; Wang et al, 1998; Werb et al, 1977).

The urokinase plasminogen activator receptor (UPAR) is a high-affinity receptor for the urokinase plasminogen activator (UPA) that potentiates and focuses uPA-mediated plasminogen activation to the cell surface (Behrendt et al, 1995; Cubellis et al, 1986; Ellis et al, 1991; Vassalli et al, 1985). In recent years, considerable evidence has accumulated that UPAR also takes part in cellular processes that are unrelated to plasminogen activation, including ligand internalization, cell adhesion, cell migration, chemotaxis, and mitogenic signal transduction (Aguirre Ghiso et al, 1999; Busso et al, 1994; Gyetko et al, 1994; Nykjaer et 
al, 1992; Resnati et al, 1996; Wei et al, 1996). These auxiliary functions of UPAR are proposed to be executed through the reversible binding of UPAR to UPA, UPA:plasminogen activator inhibitor complexes, several classes of integrins, the extracellular matrix glycoprotein vitronectin, and possibly other ligands (Deng et al, 1996; Ossowski and Aguirre-Ghiso, 2000; Preissner et al, 2000; Wei et al, 1994, 1996).

The uPAR-associated protein (UPARAP/Endo180) is a newly discovered transmembrane glycoprotein that was identified through its specific interaction with receptor-bound pro-uPA on the surface of certain cultured cells (Behrendt et al, 2000). UPARAP/ Endo180 was also independently identified as a constitutive endocytic recycling glycoprotein (Endo180) that is present on the surface of fibroblasts, endothelial cells, and macrophages (Sheikh et al, 2000), and as a transcript with the capacity to encode a novel macrophage mannose receptor type $C$ lectin that was present in an expressed sequence tag database $\mathrm{Wu}$ et al, 1996). uPARAP/Endo180 is the fourth member of the recently recognized macrophage mannose receptor family of large, multidomain, type- 1 transmembrane glycoproteins (Engelholm et al, 2001). The other members of the family are the macrophage mannose receptor, the receptor for secretory phospholipase $A_{2}$, and the DEC-205/MR6 protein (Ishizaki et al, 1994; Jiang et al, 1995; Lambeau et al, 1994; McKay et al, 1998; Taylor et al, 1990). The family is distinguished by a unique and highly conserved domain structure consisting of an $\mathrm{N}$-terminal, cysteine-rich domain homologous to ricin B lectin domains, a fibronectin type-II-like domain (Fn-II), a series of 8 to 10 consecutive C-type carbohydrate recognition domains, a transmembrane domain, and a short cytoplasmic tail (Bateman et al, 1999; Engelholm et al, 2001; Sonnhammer et al,1998). The N-terminal cysteinerich domain may mediate protein-carbohydrate or protein-protein interactions (Martinez-Pomares et al, 1999). Fn-Il domains are typically associated with collagen binding (Banyai et al, 1990). Indeed, the Fn-II domain in the secretory phospholipase $A_{2}$ receptor is a binding site for collagens type I and IV (Ancian et al, 1995). In uPARAP/Endo-180, this domain likely mediates the specific high-affinity binding of UPARAP/Endo180 to collagen V (L Engelholm, N Behrendt, and T Bugge, 2000; unpublished data), suggesting that collagen binding could be a general feature of this protein family. The carbohydrate recognition domains that have been structurally defined so far may function as calciumdependent carbohydrate interaction domains, although the relevance of carbohydrate binding to the activities of all the members of the family remains to be established (Engelholm et al, 2001; Hanasaki and Arita, 1999; Sheikh et al, 2000). The specific biologic functions of the four members of the macrophage mannose receptor family are not understood in detail. Based on the presence of multiple diverse types of protein-protein and proteincarbohydrate interaction domains, each member may have several distinct physiologic functions, such as targeting soluble ligands to the cell surface, endocytosis of ligands, cell-cell and/or cell-matrix adhesion, and signal transduction.

Two findings reported recently by Barmina et al (1999) have further enhanced the interest in UPARAP/ Endo180 as a regulator of proteolysis in the extracellular environment. First, uPARAP/Endo180 appears to serve as a specific cell surface receptor for matrix metalloprotease-13 (MMP-13). This observation is particularly noteworthy because MMP-13 can be activated from its latent proenzyme form by uPA-mediated plasminogen activation (Carmeliet et al, 1997, 1998), and because MMP-13 is a potent collagen-degrading enzyme (Knauper et al, 1996). When bound to uPARAP, MMP-13 thus could potentially be activated by UPA (via cell surface-bound plasmin) and then degrade UPARAP/ Endo180-associated collagen V. Second, as a consequence of binding to uPARAP/Endo180, MMP-13 was reported to be internalized and degraded via the lowdensity lipoprotein receptor-related protein (LRP). LRP is an essential, widely expressed clearance receptor that is required for the endocytosis of a large number of extracellular proteases and protease:inhibitor complexes, including plasminogen activators and MMP (Strickland et al, 1995; Yang et al, 2001). LRP either directly binds and internalizes proteases and protease:inhibitor complexes, or internalizes these ligands in association with specific cofactors or cell surface receptors, including uPAR (Nykjaer et al, 1997; Olson et al, 1992; Yang et al, 2001). The functional association between UPARAP/Endo180 and the protease scavenger receptor LRP could point to a broader role of uPARAP/Endo180 in protease internalization. Taken together, these intriguing findings suggest that UPARAP/Endo180 could regulate proteolysis at several levels. The receptor may serve as a scaffold in the assembly of a collagenase activator-procollagenasecollagen substrate complex on the cell surface, promoting collagenase activation and pericellular collagen degradation. Alternatively or additionally, UPARAP/ Endo180 may also be a more general factor in the removal of proteases, protease:inhibitor complexes, and protease-digested extracellular matrix from the pericellular environment. In addition to regulating proteolysis, it is also entirely conceivable that UPARAP/ Endo180 could take part in uPAR-dependent cell adhesion, cell migration, chemotaxis, and signal transduction events.

We have characterized the expression of UPARAP/ Endo180 mRNA during murine postimplantation development as an initial step toward understanding the biologic functions of this novel protease receptor. UPARAP/Endo180 was uniformly expressed in primary ossification sites during both endochondral and intramembranous ossification, and demonstrated an intriguing coexpression with its potential interaction partners UPAR and MMP-13 during osteogenesis.

\section{Results}

\section{uPARAP/Endo180 Is Expressed during Mouse Embryonic Development}

To determine if UPARAP/Endo180 was expressed during development we first performed a Northern blot 
analysis of RNA isolated from mouse embryos at embryonic day 10.5 (E10.5), E14.5, E15.5, E16.5, and E18.5 (Fig. 1). A single transcript of approximately 6 $\mathrm{kb}$, corresponding to the predicted size of UPARAP/ Endo180 deduced from the sequence of the cloned cDNA and gene ( $\mathrm{L}$ Engelholm, $\mathrm{N}$ Behrendt, and $\mathrm{T}$ Bugge, 2000; unpublished data), could be detected at all developmental stages. There was no evidence of alternative splicing of the UPARAP/Endo180 gene during mouse embryonic development, as revealed by smaller or larger uPARAP/Endo180 transcripts. The level of expression of uPARAP/Endo180 mRNA was relatively constant from $E 10.5$ through $E 16.5$, but markedly decreased at E18.5 (Fig. 1A, upper panel). As documented previously (Mattot et al, 1995; Tuckermann et al, 2000), MMP-13, which is expressed exclusively in osteogenic tissues during development, displayed robust expression commencing at E15.5, coinciding with the onset of osteogenesis (Kaufmann, 1992; Poole, 1991) (Fig. 1A, middle panel).

\section{uPARAP/Endo180 Is Expressed in Primary Ossification Sites and Colocalizes with MMP-13}

The localization of uPARAP/Endo180 mRNA in developing mouse embryos was analyzed by in situ hybridization of whole embryo sections isolated at E10.5, E14.5, E15.5, E16.5, and E17.5. Sections were obtained from 5-7 levels of each embryo analyzed. The analysis was performed with two nonoverlapping fragments of the murine uPARAP/Endo180 cDNA to confirm the specificity of the obtained signals. An identical hybridization pattern was obtained with the two anti- sense probes (data not shown). UPARAP/Endo180 expression, as revealed by in situ hybridization, was quite restricted during postimplantation development. uPARAP/Endo180 mRNA was absent or expressed below the limit of detection throughout the developing digestive tract, cardiovascular system, urogenital tract, central and peripheral nervous system, skin, muscle, tendon, and cartilage at all the developmental stages examined (not shown). Interestingly, uPARAP/ Endo180 displayed expression in all tissues undergoing primary ossification throughout the embryo (Fig. 2). UPARAP/Endo180 mRNA expression in primary ossification sites was first detectable at E15.5, commensurate with the initiation of ossification, and the signal increased in intensity at E16.5 and E17.5 (Fig. 2 and not shown). uPARAP/Endo180 expression was apparent in both the developing bones of the viscerocranium and calvarium that are formed by intramembranous ossification (Fig. 2, A to C), as well as in the developing long bones undergoing endochondral ossification (Fig. 2, E and F) (Kaufmann, 1992). No hybridization signal was obtained with the corresponding UPARAP sense probes (Fig. 2G, and not shown). Lasky and colleagues previously reported the presence of UPARAP/Endo180 transcripts in boneforming tissues of newborn mice and attributed this expression to chondrocytes (Wu et al, 1996). In this study, however, a detailed analysis of the developing long bones revealed that UPARAP/Endo180 expression was limited to cells directly bordering the osteoid, whereas no signal was present in reserve, resting, proliferating, or hypertrophic chondrocytes. Also, no signal was detected in the primitive mesenchymal
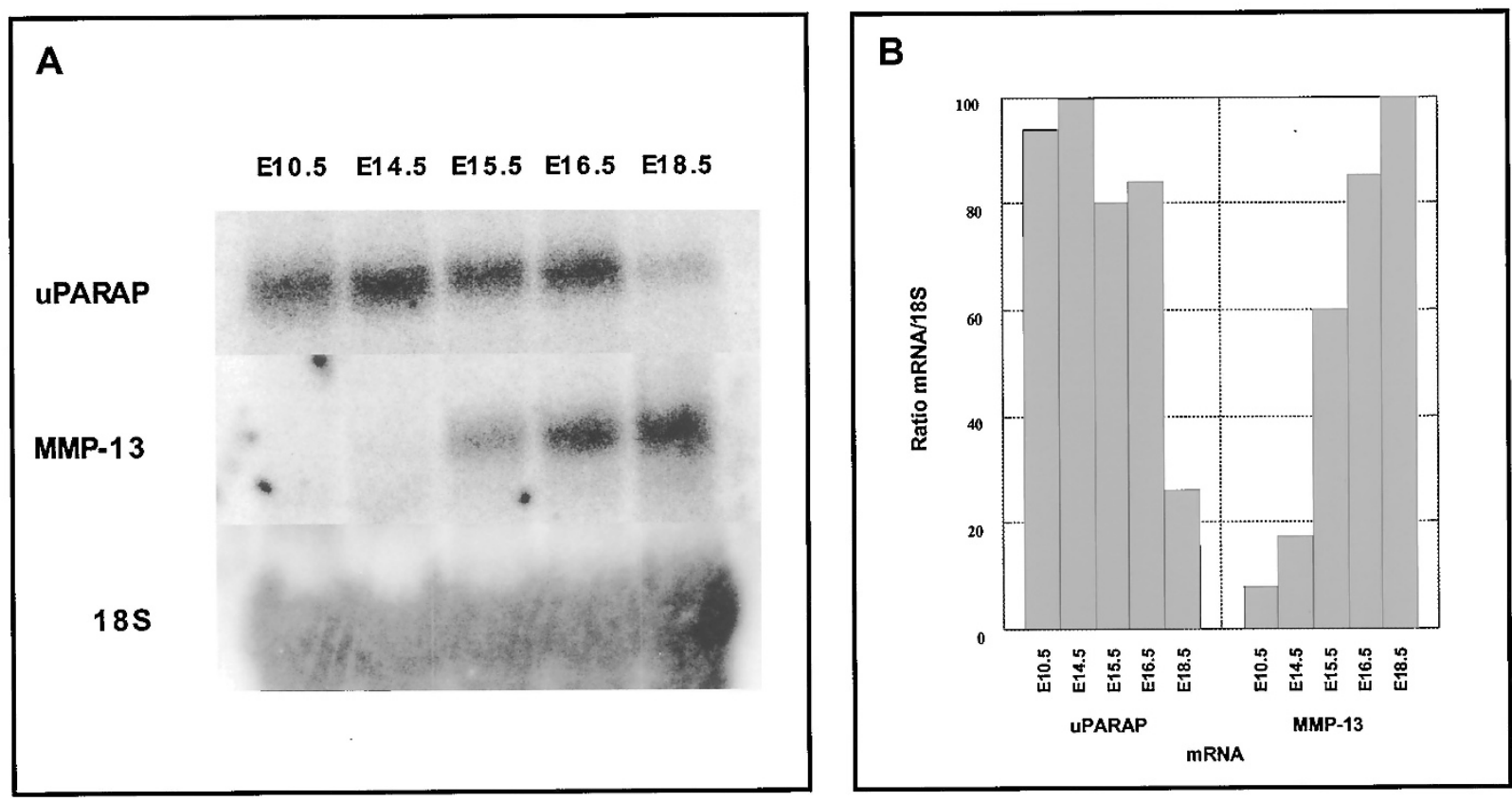

Figure 1.

Expression of urokinase plasminogen activator receptor-associated protein (UPARAP/End0180) and uPARAP/Endo180-interacting proteins during mouse embryonic development. A, Total RNA was isolated from mouse embryos at embryonic days 10.5 (E10.5) and E14.5 to E18.5 and analyzed for the expression of mRNA for UPARAP/Endo180 (upper pane), matrix metalloprotease-13 (MMP-13; middle pane), and 18S ribosomal RNA (Iower panel) by Northern blot hybridization. B, Relative levels of expression of mRNA for uPARAP/Endo180 and MMP-13 at the five developmental stages, normalized to 18S ribosomal RNA expression. 

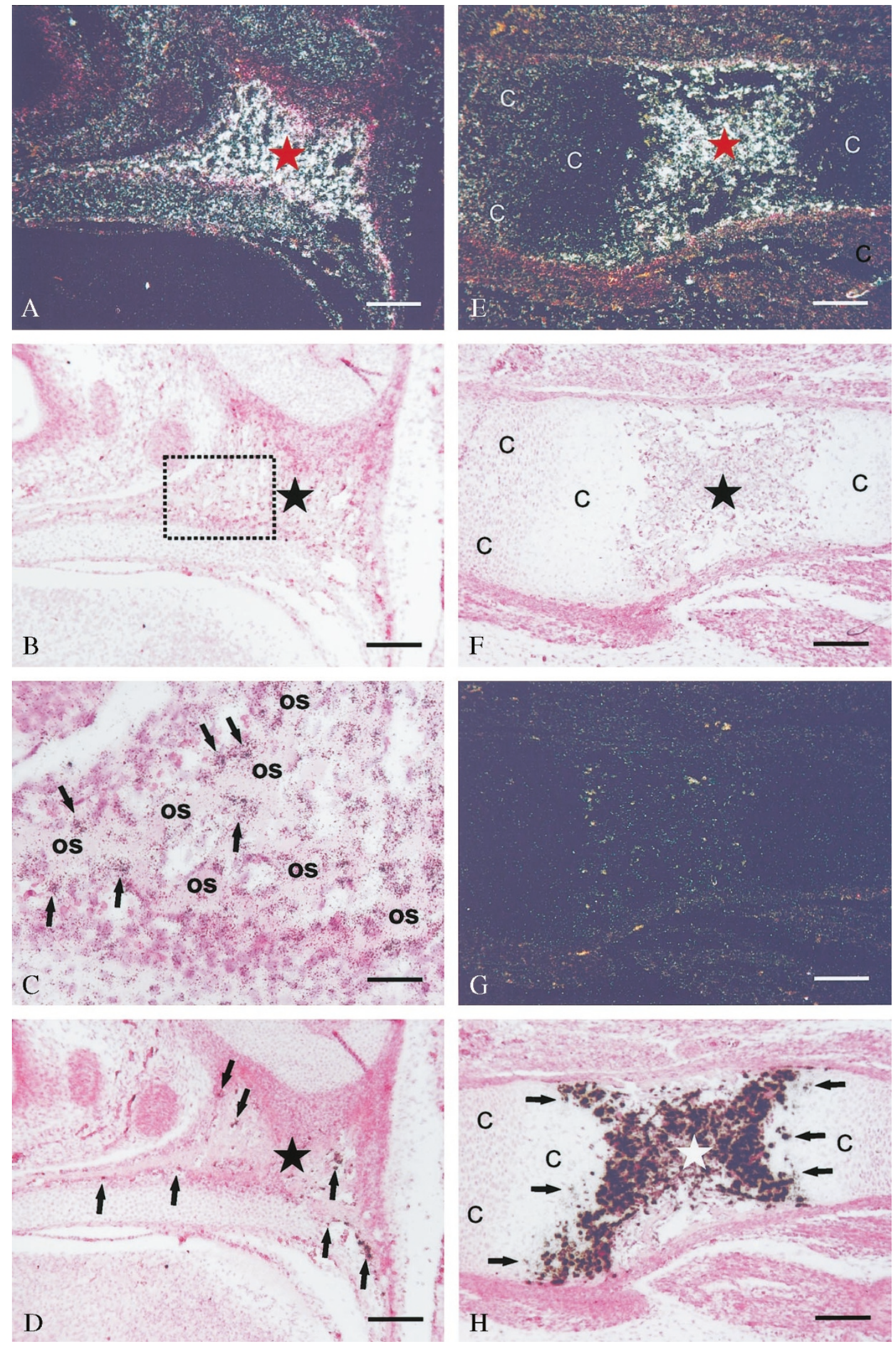

Figure 2.

Expression of uPARAP and MMP-13 mRNA in E16.5 murine osteogenic tissue. Three serial sections of formalin-fixed and paraffin-embedded embryo were hybridized with a ${ }^{35}$ S-labeled uPARAP/Endo180 antisense probe (A to C, E and F), a corresponding uPARAP/Endo180 sense probe (G), and a MMP-13 antisense probe (D and $H$ ), respectively. The left panels are representative sections of the developing frontal bone, and the right panels are representative section of the developing humerus. Dark-field illuminations in Panels A and E are of the same fields as the bright-field illuminations in Panels B and F. The framed area in Panel B is presented in larger magnification in Panel C. Both uPARAP/Endo180 mRNA and MMP-13 mRNA expression was associated with osteogenesis (indicated by stars). The signal was found 
cells of the parietal mesoderm of calvarial bones (Fig. 2, A to $\mathrm{C}$, and not shown). Primary ossification is accomplished through a concerted effort of osteoblasts, endothelial cells, and osteoclasts, each being abundant in ossification sites (Kaufmann, 1992; Poole, 1991). The morphology and spatial distribution of the uPARAP/Endo180-expressing cells was compatible with cells of the osteoblast-osteocyte lineage.

MMP-13 is expressed by osteoblasts, as well as by hypertropic chondrocytes during ossification, but not by osteoclasts and endothelial cells (Tuckermann et al, 2000). To explore the possible coexpression of UPARAP/Endo180 with its proposed interaction partner, we next performed in situ hybridization of parallel embryo sections for MMP-13 mRNA expression by ossifying tissues. A strong MMP-13 signal was displayed by cells bordering the osteoid that had a morphology similar to the cells expressing UPARAP/ Endo180 (Fig. 2, D and H, and not shown). MMP-13 was also highly expressed by cells with a morphology and spatial location compatible with hypertropic chondrocytes (Fig. $2 \mathrm{H}$, 'and not shown). In conclusion, UPARAP/Endo180 appears to be coexpressed with MMP-13 on osteoblasts during primary ossification. It should be noted, however, that the morphologic preservation of the tissue after in situ hybridization precluded the unequivocal identification of the UPARAP/ Endo180-expressing cells as osteoblasts. Expression of UPARAP/Endo180 by endothelial cells or osteoclasts can therefore not be rigorously excluded by this analysis.

\section{uPAR Is Expressed in Osteoblasts and Endothelial Cells during Ossification}

Expression of UPAR during ossification has not been reported previously. The ubiquitous expression of UPARAP/Endo180 mRNA at primary ossification sites prompted the examination of UPAR expression during development. To this end, a newly developed highly specific antibody directed against the murine UPAR (Solberg et al, 2001) was applied. Unexpectedly, this antibody demonstrated uPAR expression in all ossifying tissues (Fig. 3). Similar to uPARAP/Endo180, uPAR expression was first detectable in these tissues at E15.5, and expression increased at E16.5 and E17.5 (Fig. 3, and not shown). UPAR was expressed by osteoblasts adjacent to the osteoid as well as by more mature osteocytes embedded within the osteoid (Fig. $3, \mathrm{~B}$ and E). Endothelial cells lining the vascular canals of the developing long bones also uniformly expressed UPAR (Fig. 3E, curved arrows), whereas no expression of UPAR was detected on chondrocytes or osteoclasts. In conclusion, we find that UPAR is coex- pressed with its interaction partner UPARAP/Endo180 during primary ossification.

\section{uPARAP/Endo180, MMP-13, and uPAR TRNA Is Expressed by Cultured Osteoblasts}

Osteogenic cells were isolated from the calvarium of 3- to 5-day-old mice to further investigate the expression of UPARAP/Endo180 and its proposed interaction partners on cells of the osteoblast lineage. This cell population was selected because it contains a homogenous population of preosteoblasts that can be propagated in culture and will differentiate into mature calcifying osteoblasts-osteocytes by prolonged cultivation and by treatment with differentiating cytokines such as bone morphogenetic protein 4 (Hughes et al, 1995). This process can be monitored by determining the level of expression of the osteoblast-specific differentiation marker osteocalcin (Fig. 4A, panel e). In accordance with the results of the in situ hybridization analysis, both uPARAP/Endo180 and MMP-13 mRNA were strongly expressed by the cultured osteogenic cells at all stages of differentiation (Fig. 4A, panels a and $b$ ). Both UPARAP/Endo180 and MMP-13 mRNA were more abundantly expressed in immature osteoblasts than in mature bone osteocalcin-producing cells. However, addition of bone morphogenetic protein 4 had a minimal effect on the expression of UPARAP/Endo180 and MMP-13 mRNA, suggesting that the expression of the two genes is not strictly regulated by this osteoblast-differentiating cytokine. Interestingly, high levels of uPAR mRNA were also present in these cells (Fig. 4A, panel c). Furthermore, mRNA for collagen a1(V) chains was also abundantly expressed (Fig. 4A, panel d). Like uPARAP/Endo180 and MMP-13, the collagen a1(V) mRNA was mainly expressed by immature osteoblasts, but the level of expression was essentially unaffected by the presence of bone morphogenetic protein 4.

\section{Other Sites of uPARAP/Endo180 Expression}

Besides ossification sites, expression of UPARAP/ Endo180 was observed in a mesenchymal condensation of the midbrain (Fig. 5, and not shown). This distinct head structure, termed cephalic mesenchyme (Kaufmann, 1992), displayed a discernible uPARAP/ Endo180 signal from E14.5 to E17.5. A more detailed examination of the localization of the signal (Fig. 5C) revealed a rather uniform expression of UPARAP/ Endo180 mRNA by these mesenchymal cells, whereas expression appeared to be absent in endothelial cells of the microvasculature of this structure. Weak expression of uPARAP/Endo180 mRNA was

at sites of direct bone formation within primitive connective tissue, such as the developing frontal bone (A to $\mathrm{C}$ ), as well as in sites of bone formation from preexisting calcified cartilage, such as the humerus (E and F). In both situations, the UPARAP/Endo180 mRNA was located in cells surrounding the osteoid trabeculae (indicated by os) of the primary spongiosa, a location where endothelial cells, osteoclasts, and osteoblast-osteocytes are found (C, arrows). No signal could be detected in chondrocytes at any stage of differentiation (reserve, resting, proliferating, and hypertrophic, indicated by C). The MMP-13 mRNA-expressing cells included osteoblasts-osteocytes surrounding the area of trabeculae of the primary spongiosa in both intramembraneous ( $D$, arrows) and endochondral ossification sites. Unlike UPARAP/Endo180, MMP-13 mRNA was also seen in hypertrophic chondrocytes ( $\mathrm{H}$, arrows), located at the site of invasion by vascular vessels at the junction of the epiphysis and metaphysis. No signal was obtained with the corresponding uPARAP/Endo180 sense probe (G). Scale bars: A, B, and D to H, $160 \mu \mathrm{m} ; \mathrm{C}, 40 \mu \mathrm{m}$. 

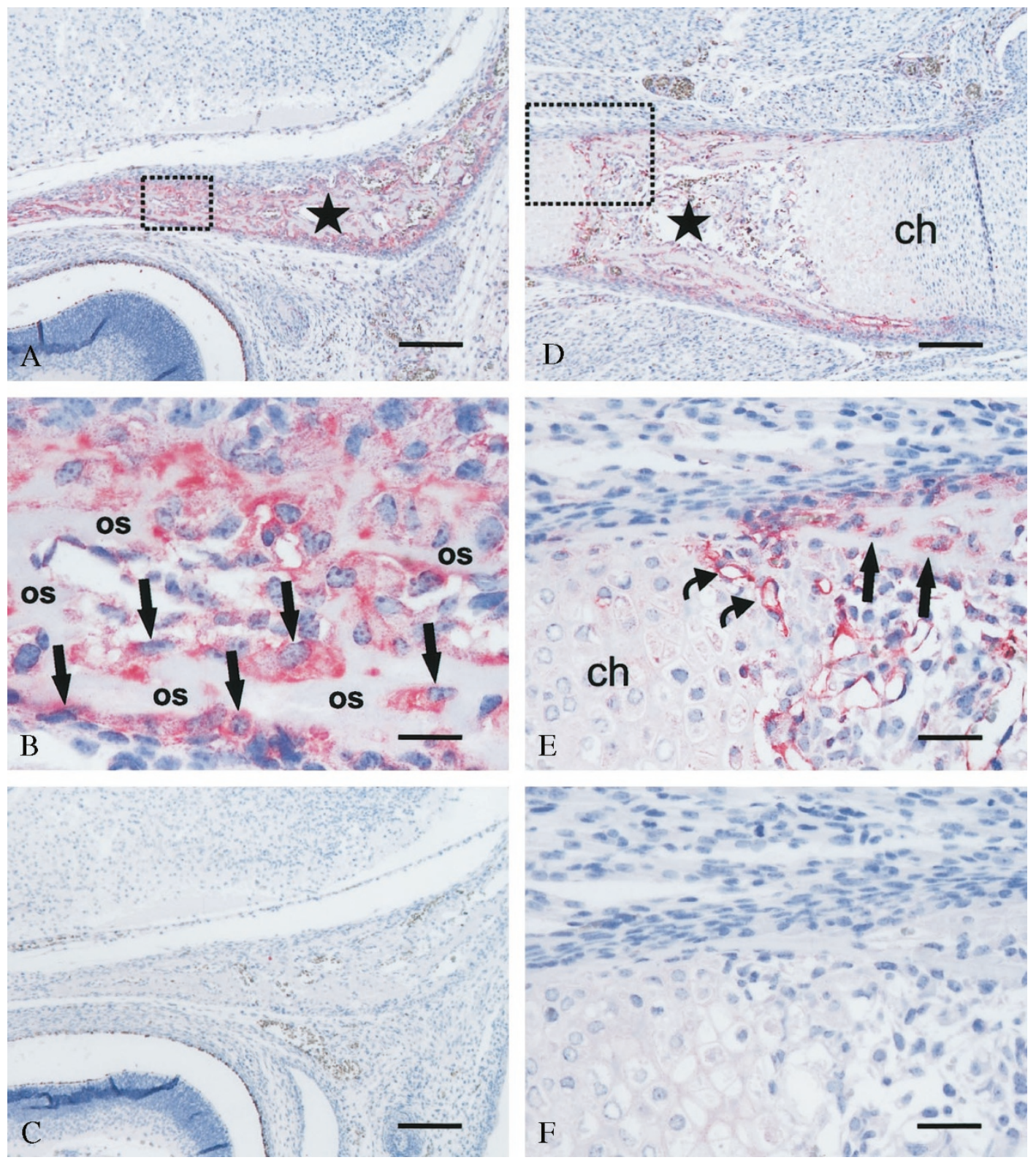

Figure 3.

Expression of urokinase plasminogen activator receptor (UPAR) immunoreactivity in E16.5 murine embryonic tissue. Sections were immunohistochemically stained for uPAR using rabbit polyclonal antibodies and tyramide amplification (A, B, D, and E) as described in "Materials and Methods." uPAR immunoreactivity (red staining) was especially evident in tissues undergoing ossification (indicated by stars) as shown for intramembraneous ossification of the frontal bone (A and B), and endochondral ossification of the humerus ( $D$ and $E)$. The framed areas in $A$ and $D$ are shown in $B$ and $E$, respectively. Staining was particularly seen in osteoblast-osteocytes (straight arrows in B and E) outlining the osteoid (os) in desmal ossification and in the capillaries (curved arrows in E) located near hypertrophic chondrocytes at the ossification front of long bones. By contrast, chondrocytes $(c h)$ were negative. Panels $C$ and $F$ are similar sections to $A$ and $E$, respectively stained with preimmune antibodies as negative control. Scale bars: A, C, and D, $160 \mu \mathrm{m} ; \mathrm{B}, 20 \mu \mathrm{m}$; E and F, $40 \mu \mathrm{m}$.

also observed in the developing lungs at $\mathrm{E} 16.5$ by cells that could not be further identified (not shown). No MMP-13 mRNA was detected in the cephalic mesenchyme or in the developing lungs (not shown). Immunohistochemical staining with the UPAR antibodies demonstrated expression of uPAR by endothelial cells in the microvasculature of both tissues, as well as in vessels throughout the embryo (not shown).

\section{Discussion}

We report that UPARAP/Endo180 is expressed by cells of the osteoblast lineage during osteogenesis in mice. This conclusion is based on (1) the sustained expression of UPARAP/Endo180 mRNA in osteoblastlike cells of all tissues undergoing primary ossification as assessed by in situ hybridization, and (2) the expression of uPARAP/Endo180 mRNA by a homogenous population of cultured primary cells of the osteoblast lineage. We also report a prominent hitherto unappreciated expression of UPAR by osteoblasts and osteocytes during primary ossification, as demonstrated both by the detection of UPAR antigen on osteoblasts-osteocytes in vivo by immunohistochemistry and by the expression of UPAR mRNA by 

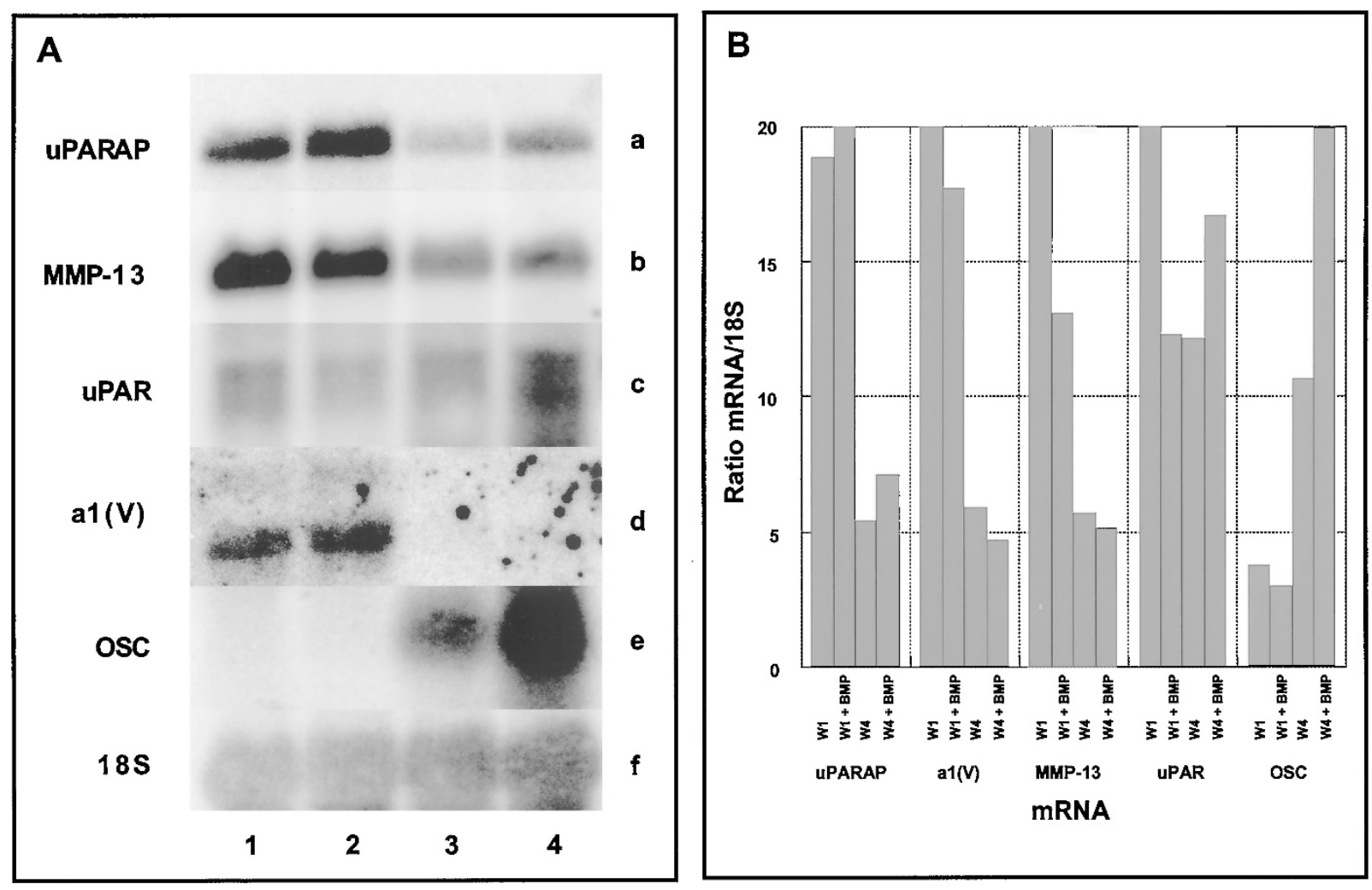

Figure 4.

Expression of UPARAP/Endo180, MMP-13, and UPAR mRNA by cultured osteoblasts. A, Cells of the osteoblast lineage were isolated from the calvaria of 3- to 5-day-old mice and cultured for 7 days (lanes 1 and 2) or 28 days (lanes 3 and 4) in the absence (lanes 1 and 3 ) or presence (lanes 2 and 4 ) of bone morphogenetic protein 4. The expression of mRNA for uPARAP/Endo180 (panel a), MMP-13 (panel b), uPAR (panel c), collagen a1(V) (panel d), osteocalcin (panel e), and 18S ribosomal RNA (panel f) was detected by Northern blot hybridization with ${ }^{32}$ P-labeled murine cDNA probes. B, Relative levels of expression of mRNA for uPARAP/End0180, MMP-13, uPAR, collagen a1(V), and osteocalcin in the four osteoblast cultures, normalized to 18S ribosomal RNA expression.

cultured cells of the osteoblast lineage. The expression of MMP-13 by osteoblasts during primary ossification is well established (Mattot et al, 1995; Tuckermann et al, 2000) and was further confirmed in this study. Collagen $\mathrm{V}$ has also been reported to be expressed by the osteoblasts during primary ossification (Wurtz et al, 1998), consistent with the expression of collagen a1(V) mRNA by cultured osteoblasts. Taken together, these data document a conspicuous coexpression of UPARAP/Endo180 with its proposed protein interaction partners, UPAR, MMP-13, and collagen $\mathrm{V}$, by cells of the osteoblast lineage during primary ossification of the developing mouse bones.

Two mechanistically distinct processes of ossification take place in the developing embryo; endochondral ossification, which occurs at the growth plates of the long bones, and intramembranous ossification, which occurs in flat bones of the viscerocranium and calvarium (Kaufman and Bard, 1999). During endochondral ossification, a mineralized collagen $\mathrm{X}$-rich cartilage model is invaded by endothelial cells that form the vasculature of the bone, by osteoblasts that deposit the primary bone matrix, and by osteoclasts that degrade and sculpture the newly formed bone matrix to form the mature bone. Intramembranous ossification does not involve the invasion of a preformed cartilage model. Instead bone matrix is deposited directly by osteoblasts differentiating in situ from primitive mesenchymal cells within connective tissuelike membranes. Intramembranous and endochondral ossification are thus mechanistically quite different processes. However, the function of the osteoblast in the two processes is the same, namely to synthesize, assemble, and deposit a specialized collagen type-lrich matrix that constitutes the organic component of the bone matrix (Ducy, 2000). Accordingly, osteoblastdeficient mice are completely devoid of bone (Komori et al, 1997; Otto et al, 1997).

Any assertions as to the function of UPARAP/ Endo180 in osteogenesis and the interaction of UPARAP/Endo180 with MMP-13, uPAR/uPA, and collagen in this process will have to be speculative in the absence of functional studies. MMP-13 is expressed solely in ossification sites during development (Mattot et al, 1995) and efficiently cleaves most types of native fibrillar collagens and probably other constituents of the extracellular matrix (Knauper et al, 1996), together strongly, implying a function in matrix turnover during bone development. However, no natural or induced MMP-13 loss of function mutations have been reported to date to corroborate this assumption. As mentioned previously, uPARAP/Endo180 has been reported to bind $\mathrm{MMP}-13$, and latent proMMP-13 can be activated efficiently by the urokinase plasminogen activation pathway (Carmeliet et al, 1997, 1998), suggesting a function of UPARAP/Endo180 in promoting 

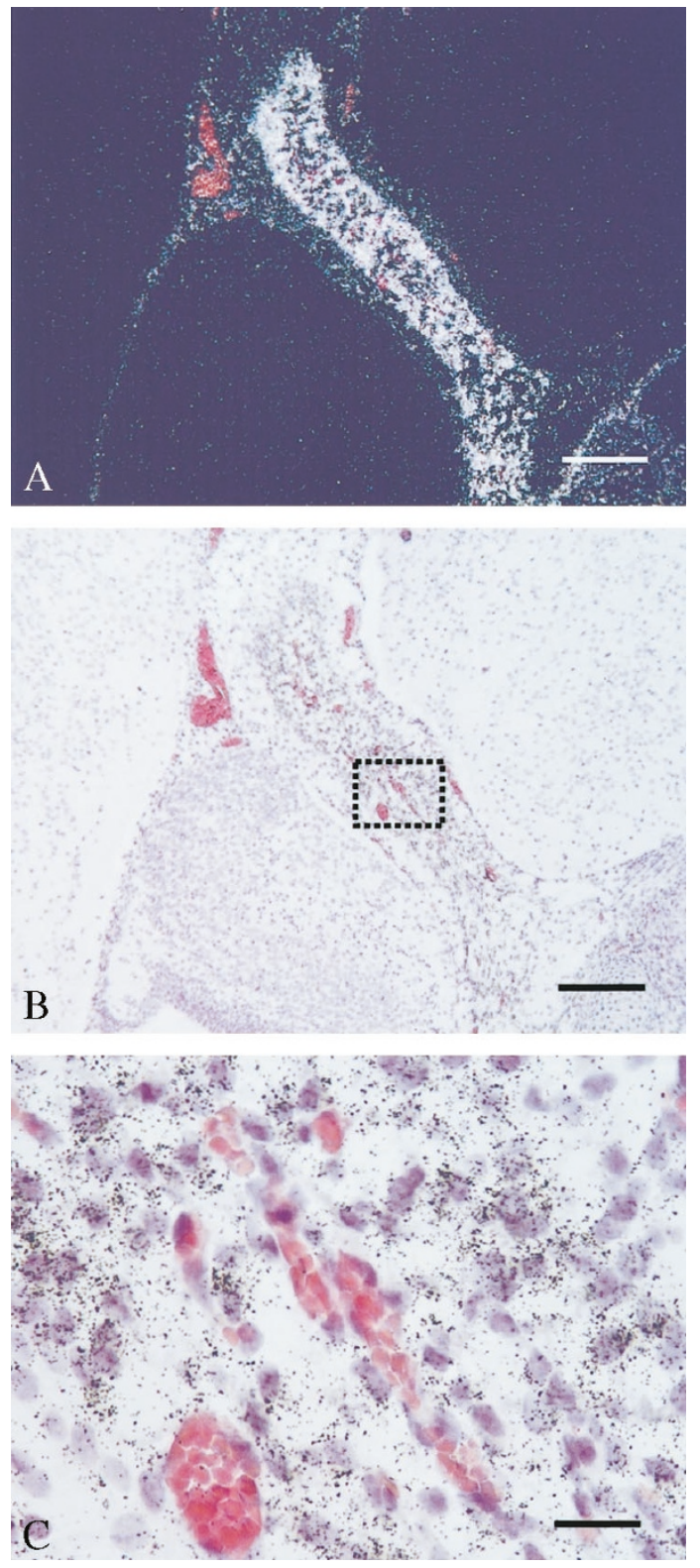

Figure 5.

Expression of uPARAP/Endo180 mRNA in E16.5 murine mesenchymal tissue. Sections of formalin-fixed and paraffin-embedded embryo were hybridized with ${ }^{35}$ S-labeled uPARAP/Endo180 antisense probe. Dark-field illumination in Panel $A$ is of the same field as the bright-field illumination in Panel $B$. UPARAP/Endo180 mRNA signal was detected in mesenchymal cells of a primitive connective tissue structure in the midbrain (A and B). A close-up (framed area in $\mathrm{B}$ ) of the cellular mesenchyme with vessels is shown in $\mathrm{C}$. Scale bars: A and B, $160 \mu \mathrm{m} ; \mathrm{C}, 20 \mu \mathrm{m}$.

proteolysis. However, UPARAP/Endo180 also mediates the internalization of MMP-13 by LRP (Barmina et al, 1999), suggesting a role of uPARAP/Endo180 in restricting proteolysis. UPARAP/Endo180 could thus potentially be a critical regulator of MMP-13 surface localization, activation, and availability during osteogenesis. UPARAP/Endo180 may also take part in uPAR-dependent processes that are irrelevant to MMP-13, including potentiation of plasminogen activation, localization of plasminogen activation, substrate presentation for plasmin, and may take part in proteolysis-independent functions of UPAR, such as cell migration, cell adhesion, signal transduction, or protease internalization. In this respect, it is noteworthy that collagen $\mathrm{V}$, unlike most collagens, is cleaved by trypsin-like enzymes, including plasmin (Behrendt et al, 2000; Niyibizi and Eyre, 1989). Mice deficient in uPAR display no overt developmental abnormalities (Bugge et al, 1995; Dewerchin et al, 1996). However, perturbations in bone morphogenesis leading to subtle alterations in the morphology of mature bones, such as those described in MMP-9-deficient mice (Vu et al, 1998), may have gone unnoticed in these mice. Our finding in this paper that osteoblasts express UPAR and UPARAP/Endo180, and that endochondral and intramembranous ossification are principal sites of UPAR and UPARAP/Endo180 expression during development, may warrant a careful examination of embryonic bone development and other osteoblastdependent remodeling processes, such as mechanical stress responses and fracture healing, in UPARdeficient mice.

Collagen $\mathrm{V}$ is a quantitatively minor component of fibrillar collagens that is present in most collagen Iand II-rich tissues, including developing bone, where it is deposited at least partially by osteoblasts (Fichard et al, 1995; Niyibizi and Eyre, 1989; Wurtz et al, 1998). Collagen $\mathrm{V}$ is believed to play a critical role in type I and II collagen fibril formation, determining the diameter of the heterotypic collagen fibrils. Mutations in the COL5 genes are linked to the classical form of EhlersDanlos Syndrome, a systemic connective tissue disorder that is characterized by disorganized and enlarged collagen fibrils (Andrikopoulos et al, 1995; Loughlin et al, 1995; Schwarze et al, 2000). The binding of UPARAP/Endo180 to collagen V could potentially modulate the deposition, adhesion to, degradation, or internalization of this collagen. This process could either involve or be independent of UPAR and MMP-13.

In conclusion, we have demonstrated the coexpression of UPARAP/Endo180 with its proposed interaction partners during murine bone development. Functional studies genetically manipulating the level of UPARAP/Endo180 will be required to unravel the function of this novel receptor in osteogenesis and other developmental processes.

\section{Materials and Methods}

\section{Northern Blot Analysis}

Embryos were dissected from the uterine horns of pregnant females, cleared of maternal tissue and snap frozen in liquid nitrogen. The frozen embryos were ground to a fine powder using a liquid nitrogen-cooled tissue grinder, and total RNA was isolated from the tissue powder using the Trizol reagent (Life Technologies, Rockville, Maryland) as recommended by the manufacturers. Pools of eight embryos were used to isolate total RNA from E10.5. Single embryos were used for RNA isolation at later developmental stages. Neonatal murine calvarial cells were prepared from the 
calvaria of 3- to 5-day-old C57BL/6J mice essentially as described (Chen et al, 1999). Briefly, the calvaria were washed for $3 \times 10$ minutes in PBS containing 4 mM EDTA. To release osteogenic cells, the washed calvaria were subjected to five 10-minute treatments with $200 \mathrm{U} / \mathrm{ml} \mathrm{CLS}-2$ bacterial collagenase (Worthington Biomedical Corporation, Freehold, New Jersey) in PBS, and the released cells were collected after each treatment. Fractions collected from the third, fourth, and fifth digestions, which are rich in osteoblast precursors and osteoblasts (Centrella et al, 1987), were pooled, washed twice in $\alpha$-MEM (Life Technologies) containing 10\% FCS (culture medium), and seeded into $10-\mathrm{cm}$ dishes at a density of 1,000-2,000 cells/ $\mathrm{cm}^{2}$. Bone morphogenetic protein 4 (R \& D Systems, Minneapolis, Minnesota) was added continuously to some cultures at $30 \mathrm{ng} / \mathrm{ml}$ to study the effect of this osteoblast-differentiating cytokine on UPARAP/ Endo180, MMP-13, uPAR, and a1(V) collagen mRNA expression. Once confluency was reached (approximately Day 7 ), the cultures were fed twice weekly with medium containing $2 \mathrm{~mm} \beta$-glycerophosphate. Total RNA was isolated from the osteogenic cells using the RNA STAT-60 reagent (Tel Test B, Friendswood, Texas) after either 1 or 4 weeks of culture. RNA was quantitated by measuring ultraviolet light absorption at $260 \mathrm{~nm}$. Twenty-microgram samples of whole embryo RNA and 6- $\mu$ g samples of osteoblast RNA were separated by electrophoresis on $1 \%$ agarose formaldehyde gels and transferred to Nytran membranes (Schleicher \& Schuell, Keene, New Hampshire) by capillary blotting. The following DNA fragments were used as probes: a 1.6-kb expressed sequence tag containing nucleotides $4303-5545$ of the murine uPARAP/Endo180 cDNA (Wu et al, 1996), a full-length murine MMP-13 cDNA (Henriet et al, 1992), a fulllength murine uPAR cDNA (Kristensen et al, 1991), a full-length murine osteocalcin cDNA (Ducy et al, 1996), and a DECA template-18S-mouse probe from Ambion (Austin, Texas). The cDNA fragments were released from their parental plasmids by digestion with appropriate restriction enzymes, purified by agarose gel electrophoresis, radiolabeled with ${ }^{32} \mathrm{P}-\mathrm{dCTP}$ by random prime labeling using the Random Primed DNA Labeling Kit (Roche Diagnostics, Indianapolis, Indiana), and purified on ProbeQuant G-50 columns (Amersham Pharmacia Biotech, Piscataway, New Jersey). Prehybridization was carried out at $65^{\circ} \mathrm{C}$ in $10 \mathrm{ml}$ QuikHyb (Stratagene, San Diego, California). The labeled DNA probe was boiled in $1 \mathrm{mg}$ salmon sperm DNA (Research Genetics, Huntsville, Alabama) and then added to the QuickHyb solution after 30 minutes of prehybridization. Hybridization was carried out for 2 hours at $65^{\circ} \mathrm{C}$. The membrane was washed for $3 \times 20$ minutes in $2 \times$ standard sodium citrate (SSC) with $0.1 \%$ SDS at $65^{\circ} \mathrm{C}$ and exposed overnight to a Phosphorlmager screen (Molecular Dynamics, Sunnyvale, California). The uPARAP/Endo 180, uPAR, MMP13, collagen a1(V), and osteocalcin mRNA signals obtained from the Phosphorlmage analysis were normalized to $18 \mathrm{~S}$ ribosomal RNA expression using ImageQuant software from Molecular Dynamics. The
Northern blot analysis of embryonic uPARAP/ Endo180 and MMP-13 expression was carried out at least twice for each developmental stage using independently isolated RNA preparations. The Northern blot analysis of UPARAP/Endo180, MMP-13, UPAR, collagen a1(V), and osteocalcin expression in cultured osteoblasts was carried out twice with RNA isolated from osteoblast culture obtained from independent calvarial preparations. Similar data were obtained in all experiments.

\section{Preparation of Mouse Embryonic Tissues for In Situ Hybridization and Immunohistochemistry}

Mouse embryos were prepared from timed matings of C57BI/6J mice (Jackson Laboratories, Bar Harbor, Maine) (midnight $=0$ days post coitum). To collect embryos, pregnant mice were anesthetized by ip injection of $0.03 \mathrm{ml} / 10 \mathrm{~g}$ of a 1:1 mixture of Dormicum (Midazolam, $5 \mathrm{mg} / \mathrm{ml}$ ) (Roche, Basel, Switzerland) and Hypnorm (Fluanison, $5 \mathrm{mg} / \mathrm{ml}$, and Fentanyl, $0.1 \mathrm{mg} /$ ml) (Janssen Pharmaceutica, Titusville, New Jersey). The mice were perfused intracardially with $20 \mathrm{ml}$ ice-cold PBS followed by $20 \mathrm{ml} 4 \%$ paraformaldehyde in PBS. The uterus was removed and fixed in 4\% PFA for a further 48 hours at $4^{\circ} \mathrm{C}$. The tissue was dehydrated and embedded in paraffin. Animal care at the National Institutes of Health and at the University of Copenhagen was in accordance with national and institutional guidelines.

\section{In Situ Hybridization}

Two fragments of the murine uPARAP/Endo180 cDNA were generated from total mouse lung RNA by RTPCR using the Titan One Tube RT-PCR System (Roche Molecular Biochemicals, Mannheim, Germany) according to the manufacturer's instructions. The amplified fragments were inserted into the PCRII-TOPO plasmid using the TOPO TA Dual Promoter cloning system (Invitrogen, Groningen, Netherlands) to generate pmUPARAP2-containing nucleotides 3147-3789 and pmuPARAP3-containing nucleotides 2567-3188 of the murine uPARAP/Endo180 cDNA (Wu et al, 1996). Plasmids containing fragments of the murine MMP-13 cDNA (pmMMP-13-485, and pmMMP-13811) have been described previously (Lund et al, 1999). Antisense and sense riboprobes were labeled with ${ }^{35}$ S-UTP (New England Nuclear, Boston, Massachusetts) by in vitro transcription of pmuPARAP2, PMUPARAP3, pmMMP-13-485, and pmMMP-13-811 using Sp6, T3, and T7 RNA polymerases (Roche) as described previously (Kristensen et al, 1991). The DNA template was digested with DNase I (Promega, Madison, Wisconsin), and nonincorporated ${ }^{35}$ S-UTP and DNA were removed by column chromatography using S-200HR microspin columns (Amersham Pharmacia Biotech). The activity was adjusted for every probe by dilution to $0.5 \times 10^{6} \mathrm{cpm} / \mu \mathrm{l}$. Five-microgram paraffinembedded whole embryo sections were deparaffinized in xylene, hydrated through graded ethanol solutions, and either digested with $5 \mu \mathrm{g} / \mathrm{ml}$ proteinase 
$\mathrm{K}$ (Roche, Basel, Switzerland) for 5 minutes at $44^{\circ} \mathrm{C}$, or boiled in $10 \mathrm{~mm}$ citric acid, pH 6.0, in a microwave oven for 5 or 10 minutes. The latter treatment was used to retain the integrity of the hypertrophic chondrocytes of the developing bones. Sections were then dehydrated and ${ }^{35}$ S-labeled probes $\left(2 \times 10^{6} \mathrm{cpm} /\right.$ slide in hybridization solution) were added. The sections were incubated overnight at $55^{\circ} \mathrm{C}$ in a humidified chamber. Sections were then washed in SSC buffers containing $0.1 \%$ SDS and $10 \mathrm{~mm}$ dithiothreitol at $150 \mathrm{rpm}$ at $55^{\circ} \mathrm{C}$ using a Bühler incubation shaker (Johanna Otto, Hechingen, Germany) for 10 minutes in $2 \times$ SSC, for 10 minutes in $0.5 \times$ SSC, and for 10 minutes in $0.2 \times$ SSC. Sections were then treated with RNase A $(20 \mu \mathrm{g} / \mathrm{ml}$ in $0.5 \mathrm{M} \mathrm{NaCl}, 1 \mathrm{~mm}$ EDTA, $10 \mathrm{~mm}$ Tris- $\mathrm{HCl}, \mathrm{pH} 7.2)$ for 10 minutes at $44^{\circ} \mathrm{C}$ to remove nonspecifically bound riboprobe. Subsequent washes were performed in $0.2 \times \mathrm{SSC}$ as specified above. Sections were dehydrated in graded ethanol solutions containing $300 \mathrm{~mm}$ ammonium acetate, soaked into an autoradiographic emulsion (llford, Cheshire, United Kingdom), exposed for 5 days (for MMP-13 specific probes) or up to 5 weeks (for UPARAP/Endo180 specific probes) and then developed. Sections were counterstained with hematoxylin and eosin, mounted in Pertex (Prohospital, Værløse, Denmark) and photographed with a Photometrics Coolsnap CCD camera, (Rober Scientific, Trenton, New Jersey) mounted on a transmission microscope (Leitz, Wetzlar, Germany).

\section{Immunohistochemistry}

Immunohistochemical staining of UPAR in murine tissues was performed with rabbit polyclonal antibodies raised against soluble recombinant murine uPAR generated in Chinese hamster ovary cells. This antibody preparation does not react with any tissues from uPAR-deficient mice in immunohistochemistry and is thus highly uPAR-specific (Solberg et al, 2001; and H Solberg, M Ploug, G Hoyer Hansen, BS Nielsen, and LR Lund, unpublished data). Five-micrometer embryo tissue sections were deparaffinized in xylene and hydrated in graded ethanol solutions. Sections were predigested with trypsin and blocked for endogenous peroxidase by immersion in $1 \%$ hydrogen peroxide for 15 minutes. The polyclonal antibodies were incubated at $10 \mu \mathrm{g} / \mathrm{ml}$ overnight at $4^{\circ} \mathrm{C}$ and then detected with biotinylated swine anti-rabbit antibodies (Dako, Glostrup, Denmark) followed by streptavidin/ horseradish-peroxidase complexes (Dako), tyramide signal amplification with biotinyl tyramine (New England Nuclear) (Bobrow et al, 1989) and, finally, streptavidin-complexed alkaline phosphatase (Dako). The sections were washed in Tris buffered saline containing $0.5 \%$ Triton $\mathrm{X}-100$ between each antibody incubation step, and developed with the fast red substrate (Kem-En-Tec, Copenhagen, Denmark) for 2 hours. Preimmune rabbit $\mathrm{lgG}$ at $10 \mu \mathrm{g} / \mathrm{ml}$ was used as a negative control.

\section{Acknowledgements}

We thank Drs. Silvio Gutkind, Karin List, and Mary Jo Danton for critically reading this manuscript, Dr. Yoshi Yamada for the murine collagen V cDNA, and Dr. Caren Gundberg for the murine osteocalcin cDNA. We also thank Mr. David Mitola, Ms. Pia Knudsen, Ms. Eva Rahtkens Nielsen, and Ms. Helle Malmstedt for their excellent technical assistance.

\section{References}

Aguirre Ghiso JA, Kovalski K, and Ossowski L (1999). Tumor dormancy induced by downregulation of urokinase receptor in human carcinoma involves integrin and MAPK signaling. J Cell Biol 147:89-104.

Ancian P, Lambeau G, and Lazdunski M (1995). Multifunctional activity of the extracellular domain of the M-type (180 $\mathrm{kDa}$ ) membrane receptor for secretory phospholipases A2. Biochemistry 34:13146-13151.

Andrikopoulos K, Liu X, Keene DR, Jaenisch R, and Ramirez $F$ (1995). Targeted mutation in the col5 $\alpha 2$ gene reveals a regulatory role for type $\mathrm{V}$ collagen during matrix assembly. Nat Genet 9:31-36.

Banyai L, Trexler M, Koncz S, Gyenes M, Sipos G, and Patthy $L$ (1990). The collagen-binding site of type-II units of bovine seminal fluid protein PDC-109 and fibronectin. Eur J Biochem 193:801-806.

Barmina OY, Walling HW, Fiacco GJ, Freije JM, Lopez-Otin C, Jeffrey JJ, and Partridge NC (1999). Collagenase-3 binds to a specific receptor and requires the low density lipoprotein receptor-related protein for internalization. J Biol Chem 274: 30087-30093.

Bateman A, Birney E, Durbin R, Eddy S R, Finn RD, and Sonnhammer EL (1999). Pfam 3.1: 1313 multiple alignments and profile HMMs match the majority of proteins. Nucleic Acids Res 27:260-262.

Behrendt N, Jensen ON, Engelholm LH, Mortz E, Mann M, and Danø K (2000). A urokinase receptor-associated protein with specific collagen binding properties. J Biol Chem 275: 1993-2002.

Behrendt N, Ronne E, and Danø K (1995). The structure and function of the urokinase receptor, a membrane protein governing plasminogen activation on the cell surface. Biol Chem Hoppe Seyler 376:269-279.

Bobrow MN, Harris TD, Shaughnessy KJ, and Litt GJ (1989). Catalyzed reporter deposition, a novel method of signal amplification: Application to immunoassays. J Immunol Methods 125:279-285.

Bugge TH, Suh TT, Flick MJ, Daugherty CC, Rømer J, Solberg H, Ellis V, Danø K, and Degen JL (1995). The receptor for urokinase-type plasminogen activator is not essential for mouse development or fertility. J Biol Chem 270:16886-16894.

Busso N, Masur SK, Lazega D, Waxman S, and Ossowski L (1994). Induction of cell migration by pro-urokinase binding to its receptor: Possible mechanism for signal transduction in human epithelial cells. J Cell Biol 126:259-270.

Busso N, Peclat V, So A, and Sappino AP (1997). Plasminogen activation in synovial tissues: Differences between normal, osteoarthritis, and rheumatoid arthritis joints. Ann Rheum Dis 56:550-557. 
Carmeliet P, Moons L, Dewerchin M, Rosenberg S, Herbert JM, Lupu F, and Collen D (1998). Receptor-independent role of urokinase-type plasminogen activator in pericellular plasmin and matrix metalloproteinase proteolysis during vascular wound healing in mice. J Cell Biol 140:233-245.

Carmeliet P, Moons L, Lijnen R, Baes M, Lemaitre V, Tipping P, Drew A, Eeckhout Y, Shapiro S, Lupu F, and Collen D (1997). Urokinase-generated plasmin activates matrix metalloproteinases during aneurysm formation. Nat Genet 17:439-444.

Carmeliet P, Schoonjans L, Kieckens L, Ream B, Degen J, Bronson R, De Vos R, van den Oord JJ, Collen D, and Mulligan $\mathrm{RC}$ (1994). Physiological consequences of loss of plasminogen activator gene function in mice. Nature 368:419-424.

Centrella M, McCarthy TL, and Canalis E (1987). Transforming growth factor beta is a bifunctional regulator of replication and collagen synthesis in osteoblast-enriched cell cultures from fetal rat bone. J Biol Chem 262:2869-2874.

Chen XD, Qian HY, Neff L, Satomura K, and Horowitz MC (1999). Thy-1 antigen expression by cells in the osteoblast lineage. J Bone Miner Res 14:362-375.

Cubellis MV, Nolli ML, Cassani G, and Blasi F (1986). Binding of single-chain prourokinase to the urokinase receptor of human U937 cells. J Biol Chem 261:15819-15822.

Danø K, Andreasen PA, Grondahl-Hansen J, Kristensen P, Nielsen LS, and Skriver L (1985). Plasminogen activators, tissue degradation, and cancer. Adv Cancer Res 44:139-266.

Deng G, Curriden SA, Wang S, Rosenberg S, and Loskutoff DJ (1996). Is plasminogen activator inhibitor- 1 the molecular switch that governs urokinase receptor-mediated cell adhesion and release? J Cell Biol 134:1563-1571.

Dewerchin M, Nuffelen AV, Wallays G, Bouche A, Moons L, Carmeliet P, Mulligan RC, and Collen D (1996). Generation and characterization of urokinase receptor-deficient mice. $\mathrm{J}$ Clin Invest 97:870-878.

Ducy P (2000). CBFA1: A molecular switch in osteoblast biology. Dev Dyn 219:461-471.

Ducy P, Desbois C, Boyce B, Pinero G, Story B, Dunstan C, Smith E, Bonadio J, Goldstein S, Gundberg C, and Bradley A (1996). Increased bone formation in osteocalcin-deficient mice. Nature 382:448-452.

Ellis V, Behrendt N, and Danø K (1991). Plasminogen activation by receptor-bound urokinase: A kinetic study with both cellassociated and isolated receptor. J Biol Chem 266:1275212758.

Engelholm L, Nielsen BS, Danø K, and Behrendt N (2001). The urokinase receptor associated protein (UPARAP/Endo180): A novel internalization receptor connected to the plasminogen activation system. Trends Cardiovasc Med 11:7-13.

Fichard A, Kleman JP, and Ruggiero F (1995). Another look at collagen V and XI molecules. Matrix Biol 14:515-531.

Gyetko MR, Todd RF 3rd, Wilkinson CC, and Sitrin RG (1994). The urokinase receptor is required for human monocyte chemotaxis in vitro. J Clin Invest 93:1380-1387.

Hanasaki K and Arita H (1999). Biological and pathological functions of phospholipase $A(2)$ receptor. Arch Biochem Biophys 372:215-223.

Henriet P, Rousseau GG, and Eeckhout Y (1992). Cloning and sequencing of mouse collagenase cDNA: Divergence of mouse and rat collagenases from the other mammalian collagenases. FEBS Lett 310:175-178.
Hughes FJ, Collyer J, Stanfield M, and Goodman SA (1995). The effects of bone morphogenetic protein-2, -4 , and -6 on differentiation of rat osteoblast cells in vitro. Endocrinology 136:2671-2677.

Ishizaki J, Hanasaki K, Higashino K, Kishino J, Kikuchi N, Ohara O, and Arita H (1994). Molecular cloning of pancreatic group I phospholipase A2 receptor. J Biol Chem 269:5897-5904.

Jiang W, Swiggard WJ, Heufler C, Peng M, Mirza A, Steinman RM, and Nussenzweig MC (1995). The receptor DEC205 expressed by dendritic cells and thymic epithelial cells is involved in antigen processing. Nature 375:151-155.

Kaufmann MH (1992). The atlas of mouse development, revised ed. San Diego: Academic Press.

Kaufmann MH and Bard TB (1999). The anatomical basis of mouse development. San Diego: Academic Press, 1-291.

Komori T, Yagi H, Nomura S, Yamaguchi A, Sasaki K, Deguchi K, Shimizu Y, Bronson RT, Gao YH, Inada M, Sato M, Okamoto R, Kitamura Y, Yoshiki S, and Kishimoto T (1997). Targeted disruption of Cbfa1 results in a complete lack of bone formation owing to maturational arrest of osteoblasts. Cell 89:755-764.

Knauper V, Lopez-Otin C, Smith B, Knight G, and Murphy G (1996). Biochemical characterization of human collagenase-3. J Biol Chem 271:1544-1550.

Kristensen P, Eriksen J, Blasi F, and Danø K (1991). Two alternatively spliced mouse urokinase receptor mRNAs with different histological localization in the gastrointestinal tract. J Cell Biol 115:1763-1771.

Lambeau G, Ancian P, Barhanin J, and Lazdunski M (1994). Cloning and expression of a membrane receptor for secretory phospholipases A2. J Biol Chem 269:1575-1578.

Loughlin J, Irven C, Hardwick LJ, Butcher S, Walsh S, Wordsworth P, and Sykes B (1995). Linkage of the gene that encodes the alpha 1 chain of type $V$ collagen (COL5A1) to type II Ehlers-Danlos syndrome (EDS II). Hum Mol Genet 4:1649-1651.

Lund LR, Rømer J, Bugge TH, Nielsen BS, Frandsen TL, Degen JL, Stephens RW, and Danø K (1999). Functional overlap between two classes of matrix-degrading proteases in wound healing. EMBO J 18:4645-4656.

Lund LR, Bjorn SF, Sternlicht MD, Nielsen BS, Solberg H, Usher PA, Osterby R, Christensen IJ, Stephens RW, Bugge TH, Danø K, and Werb Z (2000). Lactational competence and involution of the mouse mammary gland require plasminogen. Development 127:4481-4492.

Martinez-Pomares L, Crocker PR, Da Silva R, Holmes N, Colominas C, Rudd P, Dwek R, and Gordon S (1999). Cell-specific glycoforms of sialoadhesin and CD45 are counter-receptors for the cysteine-rich domain of the mannose receptor. J Biol Chem 274:35211-35218.

Mattot V, Raes MB, Henriet P, Eeckhout Y, Stehelin D, Vandenbunder B, and Desbiens $X$ (1995). Expression of interstitial collagenase is restricted to skeletal tissue during mouse embryogenesis. J Cell Sci 108:529-535.

McKay PF, Imami N, Johns M, Taylor-Fishwick DA, Sedibane LM, Totty NF, Hsuan JJ, Palmer DB, George AJ, Foxwell BM, and Ritter MA (1998). The gp200-MR6 molecule which is functionally associated with the IL-4 receptor modulates $B$ cell phenotype and is a novel member of the human macrophage mannose receptor family. Eur J Immunol 28:4071-4083. 
Niyibizi C and Eyre DR (1989). Bone type V collagen: Chain composition and location of a trypsin cleavage site. Connect Tissue Res 20:247-250.

Nykjaer A, Conese M, Christensen El, Olson D, Cremona O, Gliemann J, and Blasi F (1997). Recycling of the urokinase receptor upon internalization of the UPA:serpin complexes. EMBO J 16:2610-2620.

Nykjaer A, Petersen CM, Moller B, Jensen PH, Moestrup SK, Holtet TL, Etzerodt M, Thogersen HC, Munch M, and Andreasen PA (1992). Purified alpha 2-macroglobulin receptor/LDL receptorrelated protein binds urokinase.plasminogen activator inhibitor type-1 complex: Evidence that the alpha 2-macroglobulin receptor mediates cellular degradation of urokinase receptor-bound complexes. J Biol Chem 267:14543-14546

Olson D, Pollanen J, Hoyer-Hansen G, Ronne E, Sakaguchi K, Wun TC, Appella E, Danø K, and Blasi F (1992). Internalization of the urokinase-plasminogen activator inhibitor type- 1 complex is mediated by the urokinase receptor. $\mathrm{J}$ Biol Chem 267:9129-9133.

Ossowski L and Aguirre-Ghiso JA (2000). Urokinase receptor and integrin partnership: Coordination of signaling for cell adhesion, migration and growth. Curr Opin Cell Biol 12:613-620.

Ossowski L and Reich E (1983). Antibodies to plasminogen activator inhibit human tumor metastasis. Cell 35:611-619.

Otto F, Thornell AP, Crompton T, Denzel A, Gilmour KC, Rosewell IR, Stamp GW, Beddington RS, Mundlos S, Olsen BR, Selby PB, and Owen MJ (1997). Cbfa1, a candidate gene for cleidocranial dysplasia syndrome, is essential for osteoblast differentiation and bone development. Cell 89:765-771.

Poole AR (1991). The growth plate: Cellular physiology, cartilage assembly and mineralization. In: Hall BK and Newman SA, editors. Cartilage: Molecular aspects. Boca Raton: CRC Press, 179-211.

Preissner KT, Kanse SM, and May AE (2000). Urokinase receptor: A molecular organizer in cellular communication. Curr Opin Cell Biol 12:621-628.

Resnati M, Guttinger M, Valcamonica S, Sidenius N, Blasi F, and Fazioli $F$ (1996). Proteolytic cleavage of the urokinase receptor substitutes for the agonist-induced chemotactic effect. EMBO J 15:1572-1582.

Rømer J, Bugge TH, Pyke C, Lund LR, Flick MJ, Degen JL, and Danø K (1996). Impaired wound healing in mice with a disrupted plasminogen gene. Nat Med 2:287-292.

Sheikh H, Yarwood H, Ashworth A, and Isacke CM (2000). Endo180 an endocytic recycling glycoprotein related to the macrophage mannose receptor is expressed on fibroblasts, endothelial cells and macrophages and functions as a lectin receptor. J Cell Sci 113:1021-1032.

Solberg, H, Ploug, M, Høyer-Hansen, G, Nielsen, B S, and Lund LR (2001). The murine receptor for urokinase type plasminogen activator is primarily expressed in tissues actively undergoing remodeling. J Histochem Cytochem 49: 237-246.

Sonnhammer EL, Eddy SR, Birney E, Bateman A, and Durbin R (1998). Pfam: Multiple sequence alignments and HMM-profiles of protein domains. Nucleic Acids Res 26: 320-322.
Strickland DK, Kounnas MZ, and Argraves WS (1995). LDL receptor-related protein: A multiligand receptor for lipoprotein and proteinase catabolism. FASEB J 9:890-898.

Schwarze U, Atkinson M, Hoffman GG, Greenspan DS, and Byers PH (2000). Null alleles of the COL5A1 gene of type V collagen are a cause of the classical forms of Ehlers-Danlos syndrome (Types I and II). Am J Hum Genet 66:1757-1765.

Taylor ME, Conary JT, Lennartz MR, Stahl PD, and Drickamer K (1990). Primary structure of the mannose receptor contains multiple motifs resembling carbohydrate-recognition domains. J Biol Chem 265:12156-12162.

Tsirka SE, Gualandris A, Amaral DG, and Strickland S (1995). Excitotoxin-induced neuronal degeneration and seizure are mediated by tissue plasminogen activator. Nature 377:340344.

Tuckermann JP, Pittois K, Partridge NC, Merregaert J, and Angel P (2000). Collagenase-3 (MMP-13) and integral membrane protein 2a (Itm2a) are marker genes of chondrogenic/ osteoblastic cells in bone formation: Sequential temporal, and spatial expression of Itm2a, alkaline phosphatase, MMP13, and osteocalcin in the mouse. J Bone Miner Res 15: 1257-1265.

Vassalli JD, Baccino D, and Belin D (1985). A cellular binding site for the Mr 55,000 form of the human plasminogen activator, urokinase. J Cell Biol 100:86-92.

Vu TH, Shipley JM, Bergers G, Berger JE, Helms JA, Hanahan D, Shapiro SD, Senior RM, and Werb Z (1998). MMP-9/ gelatinase $B$ is a key regulator of growth plate angiogenesis and apoptosis of hypertrophic chondrocytes. Cell 93:411-422.

Wang YF, Tsirka SE, Strickland S, Stieg PE, Soriano SG, and Lipton SA (1998). Tissue plasminogen activator (tPA) increases neuronal damage after focal cerebral ischemia in wild-type and tPA-deficient mice. Nat Med 4:228-231.

Wei Y, Lukashev M, Simon DI, Bodary SC, Rosenberg S, Doyle MV, and Chapman HA (1996). Regulation of integrin function by the urokinase receptor. Science 273:1551-1555.

Wei Y, Waltz DA, Rao N, Drummond RJ, Rosenberg S, and Chapman HA (1994). Identification of the urokinase receptor as an adhesion receptor for vitronectin. J Biol Chem 269: 32380-32388.

Werb Z, Mainardi CL, Vater CA, and Harris ED Jr (1977). Endogenous activation of latent collagenase by rheumatoid synovial cells: Evidence for a role of plasminogen activator. N Engl J Med 296:1017-1023.

Wu K, Yuan J, and Lasky LA (1996). Characterization of a novel member of the macrophage mannose receptor type $C$ lectin family. J Biol Chem 271:21323-21330.

Wurtz T, Ellerstrom C, Lundmark C, and Christersson C (1998). Collagen mRNA expression during tissue development: The temporospacial order coordinates bone morphogenesis with collagen fiber formation. Matrix Biol 17:349-360.

Yang Z, Strickland DK, and Bornstein P (In press, 2001). Extracellular MMP2 levels are regulated by the LRP scavenger receptor and thrombospondin 2. J Biol Chem. 